\title{
Staphylococcus capitis Subspecies urealyticus
}

National Cancer Institute

\section{Source}

National Cancer Institute. Staphylococcus capitis Subspecies urealyticus. NCI Thesaurus.

Code C150878.

A subspecies of Staphylococcus capitis that is positive for urease activity and is able to produce acid from maltose aerobically. 